\title{
Subcellular Distribution and Properties of Acyl/Alkyl Dihydroxyacetone Phosphate Reductase in Rodent Livers ${ }^{1}$
}

\author{
MRIDUL K. GHOSH AND AMIYA K. HAJRA \\ Neuroscience Laboratory, Mental Health Research Institute, and Department of Biological \\ Chemistry, University of Michigan, Ann Arbor, Michigan 48109
}

Received August 26, 1985, and in revised form November 5, 1985

On subcellular fractionation, the enzyme acyl/alkyl dihydroxyacetone phosphate (DHAP) reductase (EC 1.1.1.101) in guinea pig and rat liver was found to be present in both the light mitochondrial $(\mathrm{L})$ and microsomal fractions. By using metrizamide density gradient centrifugation, it was shown that the alkyl DHAP reductase activity in the "L" fraction is localized mainly in peroxisomes. From the distribution of the marker enzymes it was calculated that about two-thirds of the liver reductase activity is in the peroxisomes and the rest in the microsomes. The properties of this enzyme in peroxisomes and microsomes are similar with respect to heat inactivation, $\mathrm{pH}$ optima, sensitivity to trypsin, and inhibition by $\mathrm{NADP}^{+}$and acyl CoA. The enzyme activity in the peroxisomes and microsomes from mouse liver is increased to the same extent by chronically feeding the animals clofibrate, a hypolipidemic drug. The kinetic properties of this enzyme in these two different organelles are also similar. From these results it is concluded that the same enzyme is present in two different subcellular compartments of liver. (c) 1986

Acyl dihydroxyacetone phosphate (acyl DHAP ${ }^{2}$ ) pathway is important for the biosynthesis of glycerolipids, especially glycerol ether lipids (1-3). Acyl DHAP and its ether analog, alkyl DHAP, are enzymatically reduced by NADPH to form the corresponding $s n$-glycerol 3-phosphate derivatives (4-6). The reductions of both acyl DHAP and alkyl DHAP are probably catalyzed by the same enzyme, i.e., acyl/alkyl DHAP reductase (EC 1.1.1.101) (6-8). Previously it was shown that this enzyme is present in all mammalian tissues analyzed and it is localized in the microsomal and mitochondrial fractions of these tissues (6). However, the recent demonstration that in

\footnotetext{
${ }^{1}$ This work was supported by Grants NS-08841 and NS-15747 from the U. S. Public Health Service, National Institutes of Health.

${ }^{2}$ Abbreviations used: DHAP, dihydroxyacetone phosphate; G-3-P, sn-glycerol 3-phosphate; DTT, dithiothreitol.
}

rodent livers DHAP acyltransferase, the first enzyme of this pathway, is mainly localized in the peroxisomes (9) suggests that the reductase may also be localized in peroxisomes and not in mitochondria. Preliminary evidence indicated that the reductase is indeed present in the peroxisomal fraction of liver (9); however, compared to the DHAP acyltransferase, relatively more reductase activity was found to be present in the microsomal fraction. This nonperoxisomal localization of the reductase is also evidenced by the finding that although DHAP acyltransferase is absent in the cultured skin fibroblasts and leukocytes of Zellweger cerebrohepatorenal syndrome patients (who lack peroxisomes), the reductase activity is almost normal (10). This dual distribution naturally raises the question of whether or not the same enzyme is present in both peroxisomes and endoplasmic reticulum. Therefore, the subcellular distribution and the properties 
of the reductase in different fractions of rodent livers and its induction by the administration of clofibrate to the animals were studied in detail. The results of these studies are presented here.

\section{MATERIALS AND METHODS}

NADPH, NADH, NADP ${ }^{+}$, palmitoyl CoA, DHAP, G-3-P, eytochrome $c$, D-glucose 6-phosphate, and $\beta$ glycerophosphate were obtained from Sigma Chemical Company (St. Louis, Mo.). Fatty acid poor bovine serum albumin was obtained from Miles Laboratories (Elkhart, Ind.). Metrizamide (analytical grade) was obtained from Accurate Chemical Co. (Westbury, N. Y.).

$B-\left[4^{-8} H\right] N A D P H$ was prepared from $D-\left[1-^{-8} \mathrm{H}\right]$ glucose and purified by DEAE-Sephacel chromatography as described (11). Aliquots of the purified $\left[{ }^{3} \mathrm{H}\right] \mathrm{NADPH}$ eluted with the $\mathrm{NaCl}$ gradient were lyophilized and stored at room temperature in the dark under vacuum over Drierite. NADPH stored under such conditions was found to remain stable for several months. Before use, the dry $\left[{ }^{8} \mathrm{H}\right] \mathrm{NADPH}$ was dissolved in water and nonradioactive NADPH was added to make the desired specific activity (usually $5000 \mathrm{cpm} / \mathrm{nmol}$ ) and the solution was stored at $4^{\circ} \mathrm{C}$ for not more than 2-3 days. [ ${ }^{32}$ P]DHAP and [ $\left.{ }^{32} \mathrm{P}\right] \mathrm{G}-3$-P $\mathrm{P}$ were prepared by the enzymatic phosphorylation of dihydroxyacetone and glycerol, respectively, and purified by the barium salt precipitation method as described previously (12). 1O-Hexadecyl DHAP and palmitoyl DHAP were synthesized by phosphorolysis of the corresponding diazoacetones (13).

The subcellular fractionation of guinea pig liver was done according to de Duve and co-workers (14) with slight modifications as described previously (15). Five fractions, i.e., nuclear (sedimenting at $6000 \mathrm{~g}_{\min }$ ), mitochondrial $\left(33,000 g_{\min }\right)$, light mitochondrial $\left(250,000 g_{\min }\right)$, microsomal $\left(6 \times 10^{6} g_{\min }\right)$, and cytosol (>6 $\times 10^{6} g_{\min }$ ), were stored in $0.25 \mathrm{M}$ sucrose at $-20^{\circ} \mathrm{C}$ in small aliquots. The fractions were rapidly thawed hefore use and were not reused. The liver postnuclear supernatant was also fractionated in linear metrizamide density gradient (20-50\%) centrifugation using a vertical rotor as described elsewhere (16). Metrizamide density gradient centrifugation (16) was also used to prepare peroxisomes from guinea pig liver light mitochondrial fraction.

Acyl/alkyl DHAP reductase was assayed by measuring the formation of labeled lipid from hexadecyl DHAP and B-[4- $\left.{ }^{8} \mathrm{H}\right]$ NADPH. An emulsion of hexadecyl DHAP (or palmitoyl DHAP when necessary) was made by sonicating $1.0 \mu \mathrm{mol}$ of lipid with $2 \mathrm{mg}$ of Tween 20 in $0.5 \mathrm{ml}$ of $50 \mathrm{mM}$ Tris- $\mathrm{HCl}$ buffer $(\mathrm{pH}$ 7.5). An aliquot (generally $0.05 \mathrm{ml}$ ) of the emulsion was added to the incubation mixture. The final assay mixture contained $33.3 \mathrm{~mm}$ potassium phosphate buffer (pH 6.5), NaF (10 mM), EDTA (0.66 mM), Tris$\mathrm{HCl}(4 \mathrm{mM})$, Tween $20(0.2 \mathrm{mg})$, hexadecyl DHAP $(0.1$ $\mu \mathrm{mol}), \mathrm{B}-\left[4-{ }^{8} \mathrm{H}\right] \mathrm{NADPH}\left(67 \mu \mathrm{M}, 5 \times 10^{6} \mathrm{cpm} / \mu \mathrm{mol}\right)$, and enzyme in a total volume of $0.6 \mathrm{ml}$. After $15 \mathrm{~min}$ incubation at $37^{\circ} \mathrm{C}$, the labeled lipid formed was extracted and washed under acidic conditions and the radioactivity was determined as described before (6).

The following marker enzymes were assayed by the published procedures as indicated: catalase (17), acid phosphatase $(18,19)$, succinate-cytochrome $c$ reductase (20), glucose-6-phosphatase (21), and lactate dehydrogenase (22). DHAP acyltransferase and G-3-P acyltransferase were assayed by measuring the formation of radioactive lipid from either $\left.{ }^{32} \mathrm{P}\right] \mathrm{PHAP}$ or $\left[{ }^{32} \mathrm{P}\right] \mathrm{G}-3-\mathrm{P}$ as described previously (23). Protein was determined by Lowry's method using bovine serum albumin as a standard (24). When interfering substances such as metrizamide were present, the protein was first coprecipitated with deoxycholic acid (25) before using Lowry's method.

For the administration of clofibrate, groups of mice (three in each group, $30-32 \mathrm{~g}$ each) were fed, aul livitum, powdered food containing clofibrate $(0.5 \% \mathrm{w} / \mathrm{w})$. The control mice were fed only the powdered food. The livers of the mice in each group were pooled together, homogenized, and fractionated by differential centrifugation as described above.

All other methods are the same as previously described $(6,9,12)$.

\section{RESULTS}

\section{Subcellular Distribution of Acyl/Alkyl DHAP Reductase}

The distribution of the reductase in the guinea pig liver subcellular fraction shows that this enzyme is enriched in the "light mitochondrial" and microsomal fractions (Fig. 1). In terms of total activity, the enzyme is found to be distributed in the mitochondrial ( $25 \%$ of total), light mitochondrial $(35 \%)$, and microsomal $(35 \%)$ fractions. In contrast, the distribution of DHAP acyltransferase, the first enzyme of this pathway, is $27 \%$ in the mitochondrial fraction, $59 \%$ in light mitochondrial, and $14 \%$ in the microsomes.

That most of the reductase activity present in the "light mitochondrial" fraction is indeed peroxisomal is shown by fractionating the " $\mathrm{L}$ " fraction by centrifugation through a metrizamide density gradient. In this gradient the peroxisomes are well separated from other organelles (16) and the reductase activity was found 


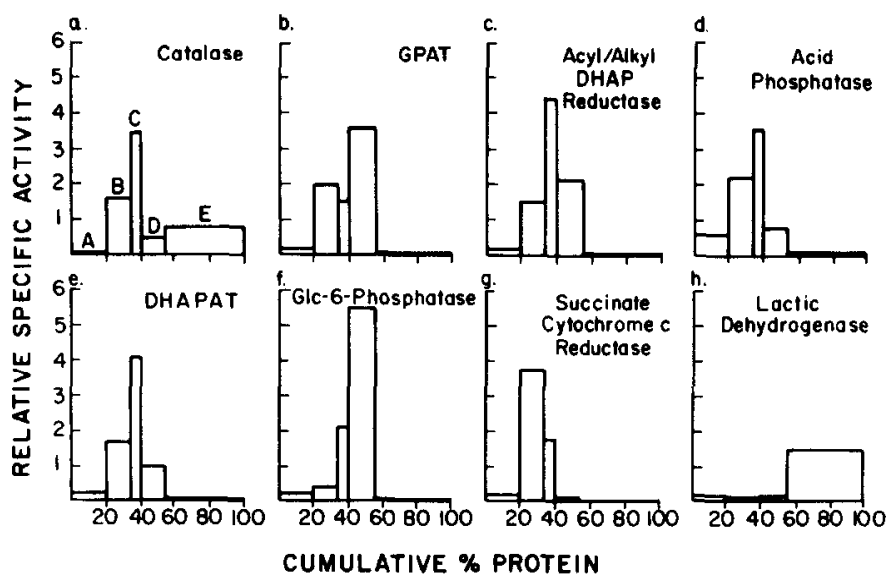

Fig. 1. Distribution pattern of acyl/alkyl DHAP reductase and other marker enzymes in guinea pig liver subcellular fractions. Relative specific activity with respect to that of homogenate is plotted against the percentage of total protein according to de Duve et al. (14). The fractions are represented according to the order in which they are isolated, i.e., from left to right: (A) nuclear fraction, (B) mitochondrial fraction, (C) light mitochondrial fraction ("L" fraction), (D) microsomal fraction, (E) cytosol. The enzymes are assayed as described in the text. The specific activities of different enzymes in the homogenate are (a) catalase, $291.1 \mathrm{units} / \mathrm{mg}$ protein; (b) G-3-P acyltransferase (GPAT), $0.47 \mathrm{nmol} / \mathrm{min} / \mathrm{mg}$; (c) acyl/alkyl DHAP reductase, $9.27 \mathrm{nmol} / \mathrm{min} / \mathrm{mg}$ protein; (d) acid phosphatase, $9.02 \mathrm{nmol} / \mathrm{min} / \mathrm{mg}$ protein; (e) DHAP acyltransferase (DHAPAT), $0.36 \mathrm{nmol} / \mathrm{min} / \mathrm{mg}$ protein; (f) glucose-6-phosphatase, $63.4 \mathrm{nmol} / \mathrm{min} / \mathrm{mg}$ protein; $(\mathrm{g})$ succinate-cytochrome $c$ reductase, 35 units/ mg protein; (h) lactic dehydrogenase, $0.208 \mu \mathrm{mol} / \mathrm{min} / \mathrm{mg}$ protein.

to be associated mostly with the peroxisomal fractions (data not shown; however, see Fig. 2). In rat liver the reductase activity is also found to be present in both peroxisomes and microsomes. This is shown in Fig. 2 where the liver homogenate (minus the nuclear fraction) was subjected to a metrizamide density gradient centrifugation procedure. A portion of the reductase is seen to be sedimented with the DHAP acyltransferase and catalase indicating the peroxisomal localization of the reductase. About 58\% of the reductase seems to be extraperoxisomal compared to only $33 \%$ of DHAP acyltransferase (Fig. 2).

\section{Properties of the Peroxisomal and Microsomal Acyl/Alkyl DHAP Reductase}

The properties of the reductase in the guinea pig liver peroxisomal fraction and the microsomal fraction are studied in detail. It should be noted that though the peroxisomes used did not contain any glu- cose-6-phosphatase activity (microsomal marker enzyme), the microsomal fraction contained $10-12 \%$ of the total cellular sedimentable catalase (marker enzyme for peroxisomes and microperoxisomes).

(a) $\mathrm{pH}$ optima. The activity of both the peroxisomal and microsomal enzymes was measured from $\mathrm{pH} 4.5$ to $\mathrm{pH} 9.0$ and the highest activity in both cases was found at $\mathrm{pH} 6.5$ with a broad shoulder of activity up to $\mathrm{pH}$ 8.5. The activity is not influenced by buffer composition as fairly continuous $\mathrm{pH}$ versus-enzyme activity curves were obtained even though different buffers were used (Fig. 3A).

(b) Heat stability. Both the peroxisomal and microsomal reductases are fairly heat stable. As shown in Fig. 3B heating the enzyme at $50^{\circ} \mathrm{C}$, or even at $55^{\circ} \mathrm{C}$, for $15 \mathrm{~min}$ did not diminish much of their activities. The heat stability of this enzyme in both these subcellular organelles is enhanced in the presence of the cosubstrate NADPH (Fig. 3B).

(c) Lability toward trypsin. Proteolytic enzymes with and without detergents have 

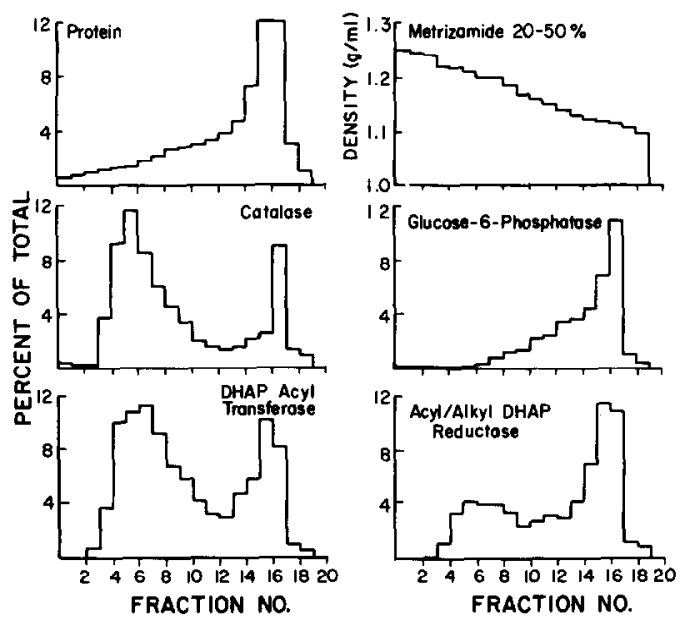

FIG. 2. Distribution of acyl/alkyl DHAP reductase with postnuclear supernatant of normal rat liver after centrifugation in a linear metrizamide gradient. The particles from the liver homogenate of rat liver were pelleted at $600 \mathrm{~g}$ for $10 \mathrm{~min}$ and the postnuclear supernatant was applied to $20-50 \%$ linear metrizamide gradient centrifugation as described elsewhere (16). Percentages of total activity are plotted against each fraction.

been extensively used to study the topography of enzymes in vesicular membranes $(26,27)$. When such experiments were done using the peroxisomal and microsomal fractions, it was found that the reductase in both the organelles is extremely labile toward treatment with trypsin in the presence or absence of the detergent Triton X100 (Fig. 3C). The enzyme remained stable when treated with Triton alone or when the trypsin was immediately neutralized by the addition of antitrypsin (Fig. 3C).

(d) Other properties. Both the peroxisomal and microsomal reductases are stable toward high concentrations (up to 10 $\mathrm{mM}$ ) of sulfhydryl group inhibitors such as $N$-ethylmaleimide and DTNB. Thiols such as DTT do not have any effect on the membrane-bound enzymes but these agents increase the stability of the enzymes after solubilization from membranes. $\mathrm{NADP}^{+}$, a product, inhibits both the peroxisomal and microsomal enzymes (see later). As described by Coleman and Bell (28), it was found that palmitoyl $\mathrm{CoA}$ at low concentration $(10 \mu \mathrm{M})$ inhibited both the microsomal and peroxisomal enzyme to the same
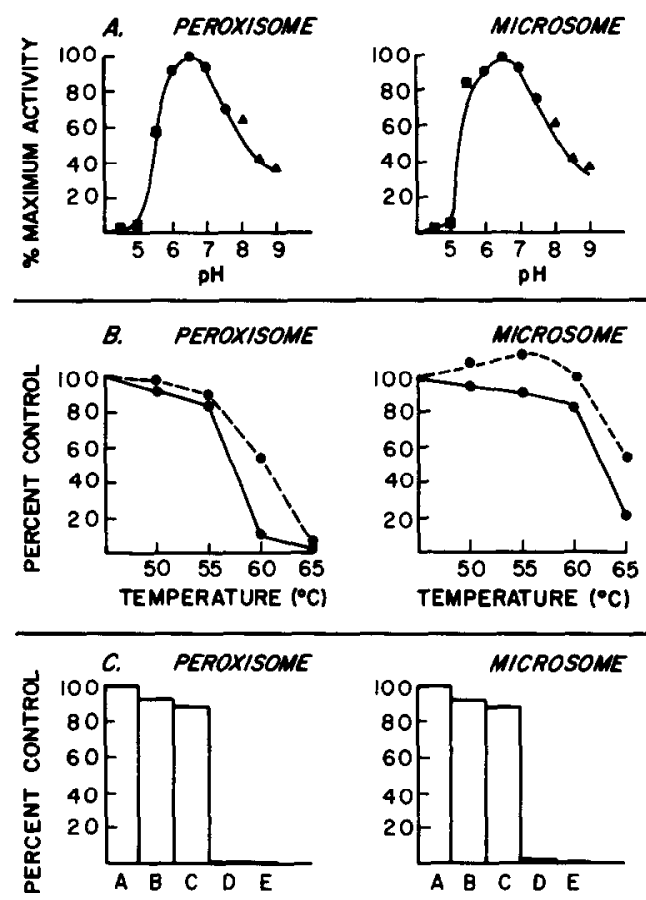

FIG. 3. (A) Effect of $\mathrm{pH}$ on the activity of acyl/alkyl DHAP reductase. The activity of both peroxisomal and microsomal enzymes was determined at different $\mathrm{pH}$ values. Different buffers $(0.5 \mathrm{M})$ were used to different $\mathrm{pH}$ values: acetate buffers from $\mathrm{pH} 4.5$ to 5.5 ; potassium phosphate buffer from $\mathrm{pH} 6.0$ to 7.5 range; Tris-HCl buffer from $\mathrm{pH} 8.0$ to 9.5. Results are expressed in percent of maximum activity which are 72 $\mathrm{nmol} / \mathrm{min} / \mathrm{mg}$ for peroxisomes and $14.1 \mathrm{nmol} / \mathrm{min} /$ mg for microsome. (B) Effect of heat on the enzymatic reduction of alkyl DHAP by microsomal and peroxisomal DHAP reductase. Samples of peroxisomes and microsomes were heated for $15 \mathrm{~min}$ at different temperatures in the absence (-) and presence (- - ) of $0.2 \mathrm{mM}$ NADPH followed by rapid cooling in ice water. The aliquots were assayed for reductase activity at $37^{\circ} \mathrm{C}$ as described in the text. (C) Effect of trypsin treatment on peroxisomal and microsomal acyl/alkyl DHAP reductase. Peroxisomes $(0.36 \mathrm{mg}$ protein) and microsomes ( $0.18 \mathrm{mg}$ protein) were incubated at room temperature in the presence of [A] buffer (10 mM Tris$\mathrm{HCl}, \mathrm{pH} 7.4$, in $0.25 \mathrm{M}$ sucrose), [B] $0.05 \%$ Triton $\mathrm{X}$ 100 in buffer, [C] trypsin inactivated with soybean trypsin inhibitor, [D] trypsin $(0.02 \mathrm{mg})$ together with Triton, and [E] trypsin (0.02 $\mathrm{mg})$ alone. After $10 \mathrm{~min}$ incubation at room temperature, trypsin inhibitor $(0.2$ $\mathrm{mg}$ ) was added to [D] and [E] to stop the trypsin digestion. DHAP acyltransferase and acyl/alkyl DHAP reductase activity were determined in aliquots of these samples. The values are expressed as percentages of activity relative to the control $(82 \mathrm{nmol} /$ $\mathrm{min} / \mathrm{mg}$ protein for peroxisomes and $15 \mathrm{nmol} / \mathrm{min} /$ mg protein for microsomes). 
extent ( $75 \%)$. The enzymes from both the subcellular organelles can be solubilized with detergents in the presence of high concentration of salt $(\mathrm{KCl})$ and the solubilized enzyme(s) is stabilized by the addition of the cosubstrate NADPH [Ref. (7) and also Ghosh and Hajra (unpublished experiments)].

\section{Kinetic Properties}

Both the peroxisomal and microsomal reductases follow regular Michaelis-Menten kinetics when the NADPH concentrations are varied keeping the concentrations of alkyl DHAP and acyl DHAP a constant. The $K_{m}$ and $V_{\max }$ values obtained from such experiments are given in Table I. As described previously $(6,29), \mathrm{NADH}$ at high concentrations can also be utilized by the enzyme to reduce acyl DHAP or alkyl DHAP. The kinetic constants obtained by using NADH as a cosubstrate are given in Table I. Hyperbolic curves were also obtained when NADPH concentration was kept constant ( $66 \mu \mathrm{M})$ varying the concentrations of alkyl DHAP. However, in this case at high concentrations of alkyl DHAP deviations from linearity (reciprocal plot) were observed probably because of the inhibition of the enzyme by high concentra- tions of alkyl DHAP. The apparent $K_{m}$ of alkyl DHAP is given in Table I.

$\mathrm{NADP}^{+}$acts as a competitive inhibitor of NADPH for both the peroxisomal and microsomal enzymes. As shown in Fig. 4, the apparent $K_{m}$ values of the enzymes for NADPH are increased in the presence of $\mathrm{NADP}^{+}$. The $K_{i}$ values for $\mathrm{NADP}^{+}$calculated from these results are $2.1 \mu \mathrm{M}$ for the peroxisomal and $1.8 \mu \mathrm{M}$ for the microsomal enzyme.

\section{Effect of Feeding Clofibrate}

A number of hypolipidemic drugs when fed to rodents cause a proliferation of peroxisomes in liver and induce a number of peroxisomal and microsomal enzymes (30, 31 ). When mice were chronically fed clofibrate, a hypolipidemic drug, for 7 days an increase of $55-70 \%$ of the total liver acyl/ alkyl DHAP reductase was observed. As described previously (31), the liver DHAP acyltransferase activity in these animals was increased by $100-120 \%$ and the catalase activity by $50-70 \%$. The distribution of the reductase between the peroxisomes and microsomes in mouse liver is similar to those found in guinea pig and rat liver. The increase in activity of the reductase after clofibrate administration is found to

TABLE I

Kinetic Constants for Substrates and Cosubstrates of Alkyl DHAP Reductase

\begin{tabular}{|c|c|c|c|c|}
\hline & \multicolumn{2}{|c|}{ Peroxisomes } & \multicolumn{2}{|c|}{ Microsomes } \\
\hline & $\begin{array}{c}V_{\max } \\
(\mathrm{nmol} / \mathrm{min} / \mathrm{mg} \\
\text { protein) }\end{array}$ & $\begin{array}{c}K_{m} \\
(\mathbf{m M})\end{array}$ & $\begin{array}{c}V_{\max } \\
(\mathrm{nmol} / \mathrm{min} / \mathrm{mg} \\
\text { protein) }\end{array}$ & $\begin{array}{c}K_{m} \\
(\mathrm{mM})\end{array}$ \\
\hline $\mathrm{NADPH}^{a}$ & 242 & 0.08 & 23.8 & 0.02 \\
\hline $\mathrm{NADPH}^{a}$ (in presence of & & & & \\
\hline $\left.100 \mu \mathrm{M} \mathrm{NADP}^{+}\right)$ & 242 & 0.13 & 23.8 & 0.07 \\
\hline $\mathrm{NADH}^{a}$ & 44 & 0.80 & 8.3 & 0.08 \\
\hline Hexadecyl DHAP ${ }^{b}$ & 236 & 0.05 & 19.8 & $<0.01$ \\
\hline $\mathrm{NADPH}^{c}$ & 262 & 0.06 & 20.8 & 0.02 \\
\hline
\end{tabular}

Note. Values were obtained from double-reciprocal plots of rate vs substrate concentrations. The best-fit line was drawn through all the points and values were obtained using one enzyme preparation for all the experiments.

${ }^{a} O$-Hexadecyl DHAP $(170 \mu \mathrm{M})$ was used as the substrate.

${ }^{b} \mathrm{NADPH}$ concentration was $66 \mu \mathrm{M}$.

${ }^{c}$ Palmitoyl DHAP $(170 \mu \mathrm{M})$ was used as the substrate. 

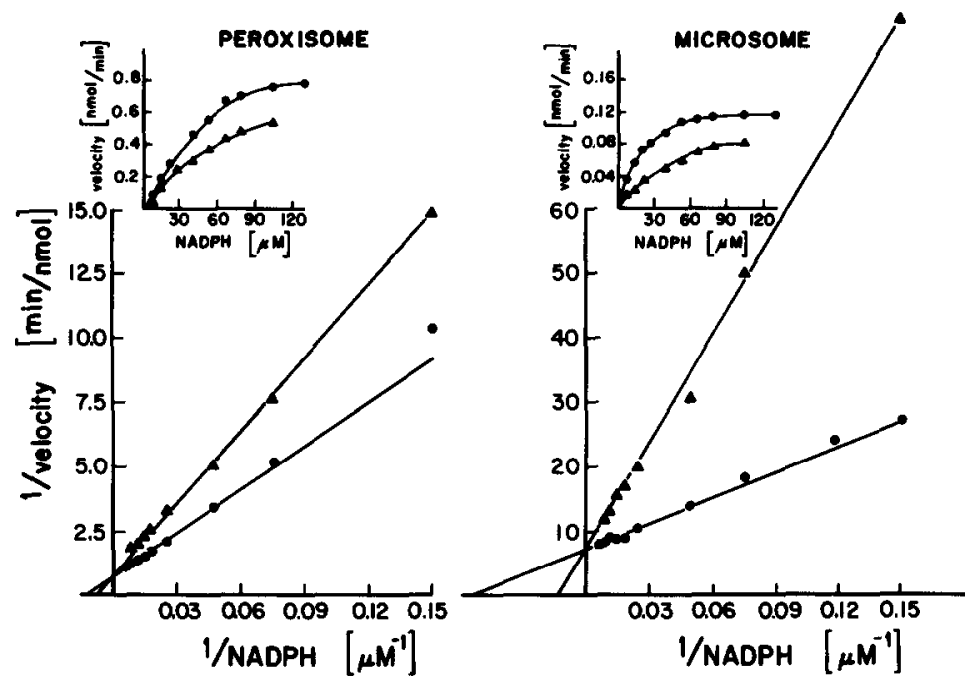

FIG. 4. Effect of increasing concentration of NADPH on the rate of acyl/alkyl DHAP reductase activity in the presence and absence of $\mathrm{NADP}^{+}$. The assays were carried out as described under Materials and Methods using alkyl DHAP $(170 \mu \mathrm{M})$ as substrate and varying concentrations (0-133 $\mu \mathrm{M})$ of NADPH and a fixed concentration $(100 \mu \mathrm{M})$ of $\mathrm{NADP}^{+}$in a total volume of $0.6 \mathrm{ml}$.

be similar ( $160 \%$ of the control) in both the microsomal and peroxisomal fractions (Table II). A single time-course experiment indicates that there was an equal rate of increase in the activity of the enzyme in microsomal and peroxisomal fractions from Day 1 to Day 5 after which the activities reached a plateau of $170 \%$ of normal controls.

\section{DISCUSSION}

Results presented here indicate that the acyl/alkyl DHAP reductase has a dual subcellular distribution in liver. If it is assumed that particulate-bound catalase is the marker enzyme for peroxisomes and glucose-6-phosphatase is the marker enzyme for microsomes, then it can be calculated from the data presented in Figs. 1 and 2 that $65-70 \%$ of the reductase is in peroxisomes and $30-35 \%$ in microsomes. However, these estimates may not be accurate because the microsomal fraction may contain membrane fragments of peroxisomes which contains no catalase and also the microperoxisomes with unknown amounts of catalase. In this respect membrane-bound DHAP acyltransferase probably would be a better marker enzyme for peroxisomes and microperoxisomes. In comparison to the DHAP acyltransferase, the liver microsomal fraction contains 20$25 \%$ more of acyl/alkyl DHAP reductase.

In both peroxisomes and microsomes the reductase activity was lost after a brief

TABLE II

Effect of Clofibrate Administration on Mouse LIVER ACYL/ALKYL DHAP REDUCTASE

\begin{tabular}{lcc}
\hline & \multicolumn{2}{c}{$\begin{array}{c}\text { Specific activity } \\
\text { (nmol/min/mg protein) }\end{array}$} \\
\cline { 2 - 3 } \multicolumn{1}{c}{ Fraction } & Control & Clofibrate-fed \\
\hline Homogenate & 6.2 & 9.1 \\
S 1 (postnuclear & & \\
$\quad$ supernatant) & 7.3 & 11.7 \\
I. Fraction & 18.6 & 29.6 \\
Microsome & 11.4 & 18.3 \\
\hline
\end{tabular}

Note. A group of mice (3 in group) were fed powdered food either mixed with clofibrate $(0.5 \mathrm{~g} / 100 \mathrm{~g}$ food, average intake of clofibrate $=23 \mathrm{mg} /$ day) or without clofibrate (control) for 7 days. They were sacrificed and acyl/alkyl DHAP reductase activity in total homogenate, postnuclear supernatant, light mitochondrial (L), and microsomal fractions of liver were determined as described in the text. 
trypsin treatment, indicating that the enzyme is exposed to the cytosolic side of the membrane. This is in contrast to the topography of DHAP acyltransferase which, from a similar kind of experiment, is postulated to be present in the luminal side of the peroxisomal and microsomal vesicles membranes $(27,32)$. This indicates that the acyl DHAP synthesized inside the peroxisomes is transported out and is reduced by the cytosolic NADPH. Therefore, our previous assumption (33) that in the acyl DHAP pathway the ${ }^{3} \mathrm{H}$ from $\mathrm{D}-\left[1-{ }^{3} \mathrm{H}\right]-$ or $\mathrm{D}-\left[3-{ }^{3} \mathrm{H}\right]$ glucose is incorporated via NADPH at the C-2 position of glycerolipid appears to be valid.

Besides the topological similarities, both the microsomal and the peroxisomal enzymes have similar properties with respect to the $\mathrm{pH}$ optimum, heat stability, substrate specificity, inhibition by $\mathrm{NADP}^{+}$, and kinetic properties. Therefore, it may be concluded that the same enzyme is present in both these organelles. The minor quantitative differences in the kinetic constants of the enzyme in peroxisomes and microsomes (Table I) may be due to the different environment of the enzyme in these two different membranes. Not many enzymes common to these two organelles are described in the literature. The only other example is carnitine acetyltransferase which has been well studied by Bieber, Tolbert, and co-workers $(34,35)$. Though carnitine acetyltransferase is soluble in peroxisomes and membrane bound in microsomes, it has been postulated from the similarities in properties that the same enzyme exists in both these organelles (35).

The presence of the same enzyme in peroxisomes and in endoplasmic reticulum raises some interesting questions regarding the biogenesis of this protein. From morphological evidence it was assumed that peroxisomes originate by budding off from endoplasmic reticulum $(36,37)$. However, in recent years Lazarow and co-workers in an extensive series of investigations provided evidence that the peroxisomal soluble and membrane-bound proteins are biosynthesized on the polysomes in cytosol and then are transferred to the peroxisomes $(38,39)$. It is possible that the acyl/alkyl DHAP reductase, synthesized in cytosol, is transported to both the peroxisomes and endoplasmic reticulum. The equal rate of induction of this enzyme in peroxisomes and microsomes after clofibrate feeding supports this hypothesis. In Zellweger cerebrohepa torenal syndrome where peroxisomes are absent, all of the reductase is probably transported to the endoplasmic reticulum, thus resulting in the normal activity (10). However, it is possible that the enzyme present in these two cellular compartments may not be exactly identical and minor differences exist between them so that these end up in the respective organelles. Only purifying the enzymes to homogeneity from these two different organelles and comparing their properties will clearly establish whether or not the same enzyme is present in peroxisomes and microsomes. Present work in this laboratory is directed toward this goal of purifying the acyl/alkyl DHAP reductase solubilized from peroxisomal and $\mathrm{mi}-$ crosomal membranes.

\section{REFERENCES}

1. HaJRa, A. K. (1977) Biochem. Soc. Trans. 5, 34-36.

2. VAN DEN BoSCH, H. (1974) Annu. Rev. Biochem. 43, 243-277.

3. HAJRA, A. K. (1983) in Ether Lipids (Mangold, H., and Paltauf, F., eds.), pp. 85-106, Academic Press, New York.

4. HaJRA, A. K., AND Agranoff, B. W. (1968) J. Biol. Chem. 243, 3542-3543.

5. WYKLE, R. L., AND SNYDER, F. (1970) J. Biol Chem. 245, 3047-3058.

6. LABELle, E. F., JR., AND HaJRA, A. K. (1972) J. Biol. Chem. 247, 5825-5834.

7. LaBelle, E. F., JR., AND HaJRA, A. K. (1974) J. Biol, Chem. 249, 6936-6944.

8. LABelle, E. F., JR., AND HaJRA, A. K. (1972) J. Biol. Chem. 247, 5835-5841.

9. HaJra, A. K., Burke, C. L., AND Jones, C. L. (1979) J. Biol. Chem. 254, 10896-10900.

10. Datta, N. S., Wilson, G. M., ANd HajRa, A. K. (1984) N. Engl. J. Med. 311, 1080-1083.

11. DAS, A. K., AND HaJRA, A. K. (1984) Biochim. Biophys. Acta 796, 178-189.

12. HajRA, A. K., AND Burke, C. L. (1978) J. Neurochem. 31, 125-134.

13. Hajra, A. K., Saraswathi, T. V., AND Das, A. K. (1983) Chem. Phys. Lipids 33, 179-193.

14. De Duve, C., Pressman, B. C., Gianetto, R., Wat- 
TIAUX, R., AND APPELMANS, F. (1955) Biochem. J. 60, 604-617.

15. JONES, C. L., AND HAJRA, A. K. (1977) Biochem. Biophys. Res. Commun. 76, 1138-1147.

16. HaJRA, A. K., AND WU, D. (1985) Anal Biochem. $148,233-244$.

17. LUCK, H. (1965) in Methods of Enzymatic Analysis (Bergmeyer, H. U., ed.), 2nd ed., pp. 885-894, Academic Press, New York.

18. BAUdHuIN, P. (1974) in Methods in Enzymology (Fleischer, S., and Packer, L., eds.), Vol. 31, pp. 356-368, Academic Press, New York.

19. Chen, P. S., JR., Toribara, T. Y., AND Warner, H. (1956) Anal. Chem. 28, 1756-1758.

20. Schnaitman, C., and Greenawalt, J. W. (1968) J. Cell Biol. 38, 158-175.

21. NoRDLIE, R. C., AND ARION, W. J. (1965) in Methods in Enzymology (Wood, W. A., ed.), Vol. 9, pp. 619-625, Academic Press, New York.

22. KoRNBERG, A. (1955) in Methods in Enzymology (Colowick, S. P., and Kaplan, N. O., eds.), Vol. 1, pp. 441-443, Academic Press, New York.

23. HAJRA, A. K., AND BURKE, C. (1978) J. Neurochem. 31, 125-134.

24. Lowry, O. H., Rosebrough, N. J., FARR, A. L., AND Randall, R. J. (1951) J. Biol. Chem. 193, 265-275.

25. Bensadoun, A., AND Weinstein, D. (1976) Anal. Biochem. 70, 242-250.

26. Coleman, R. A., AND BeLL, R. M. (1983) Enzymes 16, 605-619.
27. JONES, C. L., AND HAJRA, A. K. (1980) J. Biol Chem. 255, 8289-8295.

28. Coleman, R. A., AND BeLl, R. M. (1980) J. Biol. Chem. 255, 7681-7687.

29. Chae, K., Piantadosi, C., ANd Snyder, F. (1973) J. Biol. Chem. 248, 6718-6723.

30. REDDY, J. K., WARREN, J. R., REDDY, M. K., AND Lalwant, N. D. (1982) Ann. N. Y. Acad. Sci. 386, 81-110.

31. Das, A. K., Aquilina, J. W., and HaJRA, A. K. (1983) J. Biol. Chem. 258, 3090-3093.

32. Rock, C. O., FITZgeraLd, V., AND SNYdER, F. (1977) J. Biol. Chem. 252, 6363-6366.

33. Pollock, R. J., HajRa, A. K., AND Agranoff, B. W. (1976) J. Biol. Chem. 251, 5149-5154.

34. Markwhll, M. A. K., McGroarty, E. J., Bieber, L. L., AND Tolbert, N. E. (1973) J. Biol Chem. 248, 3426-3432.

35. Markwell, M. K., Tolbert, N. E., AND Bieber, L. L. (1976) Arch. Biochem. Biophys. 176, 479488.

36. Novikoff, P. M., Novikoff, A. B., Quintana, N., AND DAvIS, C. (1973) J. Histochem. Cytochem. 21, 540-558.

37. Novikoff, A. B., AND NovikofF, P. M. (1982) Ann. N. Y. Acad. Sci. 386, 138-152.

38. LaZAROW, P. B., ROBBI, M., FUJIKI, Y., AND WONG, L. (1982) Ann. N. Y. Acad. Sci. 386, 285-300.

39. Fujiki, Y., AND Lazarow, P. B. (1985) J. Biol. Chem. 260, 5603-5609. 